\title{
A Multi-objective Optimization Approach for Design of Worm and Worm Wheel Based on Genetic Algorithm
}

\author{
Y.K. Mogal and V.D. Wakchaure
}

\begin{abstract}
Number of conventional methods are available for solving different types of optimization problems. But due to their complexity and convergence problems these methods are not able to give optimal solution. A gear transmission problem is one of the most complex optimization problems because of relationship between different variables. A Gear design require the designer to compromise many design variables; i.e. continuous, discrete \& integer variables in order to determine best performance of gear set. Therefore researchers are now going to use Evolutionary Techniques. Genetic Algorithm (GA) is one of such technique.

In this paper the attempt has been made to optimize worm and worm wheel with multiple objectives, which takes gear ratio (i), face width of worm \& worm wheel (b) and pitch circle diameters of worm $\left(d_{w}\right) \&$ worm wheel $\left(d_{g}\right)$ as design variables. The main objective function is to minimize volume of worm and worm wheel and remaining objectives are taken as constraints such as centre distance, deflection of worm and beam strength of worm gear.
\end{abstract}

Keywords--- Genetic Algorithm, Multiobjective Optimization, Worm and Worm Wheel

\section{INTRODUCTION}

$\mathrm{O}$ PTIMIZATION is defined as process, which finds value of variables that minimize or maximize the objective function while satisfying constraints [1]. Conventional optimization methods have been widely used in various mechanical design problems. They are deterministic in nature and use only a few geometric design variables due to their complexity and convergence problems. When the number of design parameters increases, the complexity increases drastically. If the optimization problem involves the objective function and constraints that are not stated as explicit functions of the design variables or which are too complicated to manipulate, it is hard to solve by classical optimization methods [2].

Y.K.Mogal, P.G.student, Department of Mechanical Engineering, Amrutvahini College of Engineering, Sangamner, India, E-mail: ymogal1988@gmail.com

V.D.Wakchaure, Associate Professor, Department of Mechanical Engineering, Amrutvahini College of Engineering, Sangamner, India, E-mail: wvishnu@rediffmail.com

DOI: 10.9756/BIJMMI.4403
Hence it is necessary to develop more efficient and reliably technique that solves such problems. GA differs substantially from traditional optimization methods. The few most significant differences are

1] Populations of points are used for starting the procedure instead of single design point.

2] GA use only values of objective function. The derivatives are not used in search procedure

3] The objective function value corresponding to a design vector plays the role of fitness in natural genetics.

4] GA use probabilistic transition rules, not deterministic ones [3].

5] GA works with coding of parameter set, not the parameters themselves [4].

Genetic algorithm is based on evolutionary processes and Darwin's concept of natural selection. It works on the principle that, only the fittest populations will survive while the bad populations are weeded out. The same concept is extended to the mathematical optimization problems where only good design points are selected while the bad design points are neglected [5].

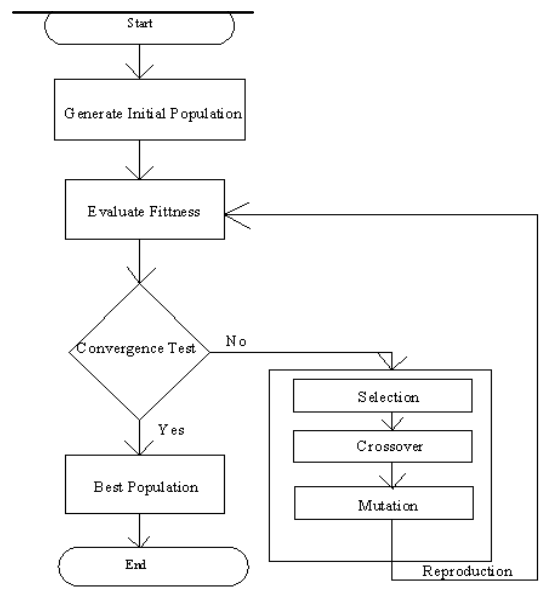

Figure 1: Flowchart of Genetic Algorithm

Figure 1 shows that an initial population is chosen randomly at the beginning and fitness of initial population individuals is evaluated. Then an iterative process starts until the termination criteria have been run across. After the evaluation of individual fitness in the population, the genetic operators, selection, crossover and mutation are applied to breed a new generation. The newly created individuals replace the existing generation and reevaluation is started for fitness of 
new individuals. The loop is repeated until acceptable solution is found [6]. In this paper Multi-objective optimization of worm and worm wheel is carried out. The main issue in design of worm and worm wheel is, it should be compact means its volume should be less, centre distance should be less, there should be no deflection of worm and also it should have high strength. All these objectives are considered here to get best performance of worm and worm wheel.

\section{LITERATURE SURVEY}

Gear design involves empirical formulas, different graphs and tables, which lead to a complicated design. Moreover, increasing demand for compact, efficient, and reliable gears forces the designer to use optimal design methodology [7]. Lot of research is carried out regarding optimization of gears using Genetic algorithm.

Gologlu et al. (2009) minimized volume of two-stage helical gear train by taking normal module, number of teeth \& face width as design variables and bending strength, contact stress as a constraint [8]. Sanchez et al. (2008) have been used GA to minimize weight of cylindrical parallel gear train. He has taken width, gear teeth numbers, normal module etc. as a design variable [9]. Chong et al. (2000) have applied GA for minimization of geometric volume of two stage gear train and simple planetary gear train. In this result, the volume of pitch diameter and face width is reduced about $40 \%$, and the error of reduction gear ratio between objective and result are about 3\% [10]. Mendi et al. (2010) optimized volume of gearbox. The gear volume obtained by GA was $1.47 \%$ lower than the gear volume obtained by analytical method [2]. Faggioni et al. (2011) presented a global optimization method focused on gear vibration reduction by means of profile modifications [11]. Feren et al. (2005) investigated multidisciplinary optimization possibility for minimum noise (sound power level) has been for cylindrical gears. Results show that the maximum decrease in the acoustic power is $10 \%$ in case of the optimum geometry, comparing to the simplest geometry case [12]. Li et al. (2008) used an adaptive Genetic Algorithm (GA) to solve the multi-objective optimization design of the reducer [13]. Barbieri et al. (2008) used Genetic Algorithms in conjunction with a suitable objective function to find suitable profile modifications for a spur gear pair [14]. Zhang (2010) established the mathematical model for optimization design of gear reducer, with the purpose of minimum volume or quality. By using genetic algorithm and genetic toolbox of MATLAB to get optimum solution quickly and accurately, the efficiency and quality of gear design is greatly improved and the production cycle is shorten [15].

From above literature we see that lot of research is carried out on spur and helical gears. But very little amount of research is carried out on worm and worm wheel. Therefore worm and worm wheel is has been taken here for optimization purpose.

\section{PRoBlem STATEMENT}

From the literature survey the problem statement of the current work is, to carry out optimization of worm and worm wheel considering different objectives. These are as follows;
1] Minimization of volume of worm and worm wheel.

2] Minimization of centre distance between worm and worm wheel.

3] Minimization of deflection of worm.

For optimization purpose worm and worm wheel, which is used for crystallization purpose in sugar factory has been selected, whose specifications are shown in Table 1.

Table 1: Specifications of Worm and Worm Wheel Assembly

\begin{tabular}{|l|l|l|l|}
\hline Sr. No. & Parameters & Worm & Worm Wheel \\
\hline 1 & Pitch circle diameter (mm) & 240 & 1560.19 \\
\hline 2 & Number of starts/teeth & 1 & 65 \\
\hline 3 & Centre distance (mm) & \multicolumn{2}{|c|}{901} \\
\hline 4 & Face width (mm) & \multicolumn{2}{|c|}{160} \\
\hline 5 & Linear pitch (mm) & 75.408 & - \\
\hline 6 & Speed (rpm) & 48 & 0.7385 \\
\hline 7 & Lead angle $\left({ }^{\circ}\right)$ & 5.71 & - \\
\hline
\end{tabular}

\section{Mathematical Modeling}

\section{A. Design Variables}

Here Gear ratio (i), Face width (b), Pitch circle diameter of worm $\left(\mathrm{d}_{\mathrm{w}}\right)$ and Pitch circle diameter of worm wheel $\left(\mathrm{d}_{\mathrm{g}}\right)$ are considered as a design variables.

$$
\mathrm{F}(\mathrm{x})=\mathrm{F}\left(\mathrm{i}, \mathrm{b}, \mathrm{d}_{\mathrm{w}}, \mathrm{d}_{\mathrm{g}}\right)=\mathrm{F}\left(\mathrm{x}_{1}, \mathrm{x}_{2}, \mathrm{x}_{3}, \mathrm{x}_{4}\right)
$$

Upper and lower bounds of design variables are, 1500 .

$$
40 \leq \mathrm{i} \leq 70,100 \leq \mathrm{b} \leq 200,150 \leq \mathrm{d}_{\mathrm{w}} \leq 280 \text { and } 1000 \leq \mathrm{d}_{\mathrm{g}} \leq
$$

\section{B. Objective Function}

The main thing in design of gear pair is, it should be compact means it should have less volume. The main objective function for the present work is to minimize volume of worm and worm wheel assembly. Main issue in formulating equation for volume is worm wheel is not solid one it looks like flywheel. That's why separate volume equations for rim, arms \& remaining portion of worm wheel have been derived using Design Data Book and Design of Machine Elements book [18]. Volume of worm is the product of area and length of worm. After combing volume of worm and worm wheel, the objective function is formulated as:

$$
\begin{gathered}
\text { Volume }(\mathrm{V})=14.310926 * \frac{\mathrm{x}_{3}{ }^{2} \mathrm{x}_{4}}{\mathrm{x}_{1}}+455.5309 \mathrm{x}_{2} \mathrm{x}_{4}+ \\
0.8382 *\left(\frac{256 \mathrm{x}_{4}{ }^{2}+\mathrm{x}_{1}{ }^{2} \mathrm{x}_{2}{ }^{2}}{\mathrm{x}_{1} \mathrm{x}_{4}}\right)^{2}+104634.67
\end{gathered}
$$

\section{Constraints}

Constraints are the conditions that must be met in the optimum design and include restrictions on design variables. These constraints define boundaries of the feasible and infeasible design space domain. The constraints considered for the optimum design of worm and worm wheel is as follows:

\section{- $\quad$ Centre Distance}

To have compact design of gear pairs, centre distance between worm and worm wheel should be less. This constraint 
tells that centre distance of optimized gear pair should be less than that of actual gear pair and the equation is formulated as [18],

$$
\frac{\frac{\mathrm{x}_{1} \mathrm{x}_{2}}{2 \sqrt{\frac{65 \mathrm{x}_{3}}{\mathrm{x}_{4}}+1}}+\mathrm{x}_{3}}{2}-901 \leq 0
$$

\section{- Centre Distance and Pitch Circle Diameter of Worm}

For maximum power transmitting capacity [16],

$$
\frac{\mathrm{a}^{0.873}}{3} \leq \mathrm{d}_{\mathrm{w}} \leq \frac{\mathrm{a}^{0.873}}{1.7}
$$

Where,

a : centre distance between worm and worm wheel

$\mathrm{d}_{\mathrm{w}}$ : Pitch circle diameter of worm

Based on this equation two equations are formulated as constraints for centre distance and pitch circle diameter of worm as follows,

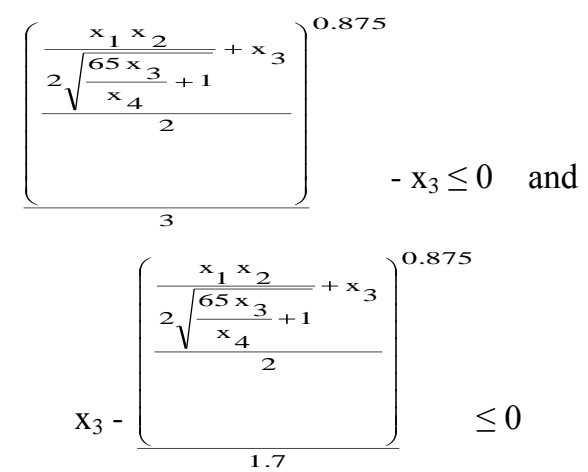

\section{- Deflection of Worm}

The worm is supported between two bearings, if the worm shaft bends too much, that is, the teeth will not mesh properly and the result will be excessive wear and early failure. So the maximum deflection is, [6], [17].

$$
\frac{\sqrt{\mathrm{F}_{\mathrm{wt}}^{2}+\mathrm{F}_{\mathrm{wr}}^{2}}}{48 \mathrm{EI}} * \mathrm{~L}^{3} \leq 0.001 \mathrm{~d}_{\mathrm{w}}
$$

Where,

$F_{w t}$ : Tangential force on worm

$\mathrm{F}_{\mathrm{wr}}$ : Radial force on worm

$\mathrm{E}:$ Modulus of Elasticity of worm material

I : Moment of inertia for worm

$\mathrm{L}:$ Distance of bearings

$\mathrm{d}_{\mathrm{w}}$ : Pitch circle diameter of worm

Based on above equation, constraints for deflection of worm is formulated as,

$$
\frac{90.887873 * \frac{\mathrm{x}_{4}{ }^{4}}{\mathrm{x}_{1}}}{\left[\mathrm{x}_{2}{ }^{2}-4{\left.\frac{\mathrm{x}_{4}}{\mathrm{x}_{1}{ }^{2}}\right] *\left[\mathrm{x}_{3}-2.4 \frac{\mathrm{x}_{4}}{\mathrm{x}_{1}}\right]^{4}}^{4}\right.} \leq 0.001 \mathrm{x}_{3}
$$

\section{- Beam Strength of Worm Gear}

We know that Beam strength of worm gear tooth is the maximum tangential load the worm gear tooth can take without tooth breakage [18]. It is given by,

$$
\mathrm{F}_{\mathrm{b}}=\sigma_{\mathrm{bg}} \mathrm{bm} \mathrm{Y} \cos \lambda
$$

Where,

$\sigma_{\mathrm{bg}}:$ Permissible bending stress for worm gear

$\mathrm{F}_{\mathrm{b}}$ :Beam strength of worm gear tooth

$b$ :Face width of worm gear

$\mathrm{m}$ : module

$\lambda:$ Lead angle of the worm

$\mathrm{Y}$ : Lewis form factor for worm gear tooth

Based on above equation constraints for beam strength of worm is formulated as,

$$
\frac{66116467.3 \mathrm{x}_{1}}{\mathrm{x}_{4} \mathrm{x}_{2} \mathrm{x}_{3}}-83.33333 \leq 0
$$

\section{IMPLEMENTATION OF GENETIC ALGORITHM}

\section{- Fitness Function}

It is the objective function you want to minimize. To use Genetic Algorithm Toolbox functions, you must first write an M-file (or else an anonymous function) that computes the function you want to optimize. You can specify the function as a function handle of the form @ simplefitness, where simplefitness.m is an M-file that returns a scalar is shown below.

$$
\begin{aligned}
& \text { function } \mathrm{y}=\text { simplefitness }(\mathrm{x}) \\
& \begin{array}{r}
\mathrm{y}=14.310926 *\left(\left(\mathrm{x}(3)^{\wedge} 2 * \mathrm{x}(4)\right) / \mathrm{x}(1)\right)+455.5309 * \mathrm{x}(2)^{*} \mathrm{x}(4)+ \\
0.0832 *\left(\left(\left(256^{*} \mathrm{x}(4)^{\wedge} 2\right)+\left(\mathrm{x}(1)^{\wedge} 2 * \mathrm{x}(2)^{\wedge} 2\right)\right) /\left(\mathrm{x}(1)^{*} \mathrm{x}(4)\right)\right)^{\wedge} 2 \\
+104034.07 ;
\end{array}
\end{aligned}
$$

\section{- Bounds}

Specify lower bounds as $[40,100,150,1000]$ and upper bounds as [70, 200, 280, 1500]

\section{- Nonlinear Constraint Function}

It defines the nonlinear constraints. Specify the function as an anonymous function or as a function handle of the form @ simpleconstraint, where simpleconstraint.m is an M-file that returns the vectors $\mathrm{c}$ and ceq as shown below. The nonlinear equalities are of the form ceq $=0$, and the nonlinear inequalities are of the form $\mathrm{c} \leq 0$.

$$
\begin{aligned}
& \text { function }[\mathrm{c}, \mathrm{ceq}]=\operatorname{simpleconstraint}(\mathrm{x}) \\
& \mathrm{c}=\left[\left(\mathrm{x}(3)+\left(\mathrm{x}(1)^{*} \mathrm{x}(2)\right) /(2 * \operatorname{sqrt}((65 * \mathrm{x}(3) / \mathrm{x}(4))+1))\right) / 2-901 ;\right. \\
& \left(\left(\left(\mathrm{x}(3)+\left(\mathrm{x}(1)^{*} \mathrm{x}(2)\right) /\left(2 * \operatorname{sqrt}\left(\left(65^{*} \mathrm{x}(3) / \mathrm{x}(4)\right)+1\right)\right)\right) / 2\right)^{\wedge} 0.875\right) / 3- \\
& \mathrm{x}(3) ; \mathrm{x}(3)-\left(\left(\left(\left(\mathrm{x}(3)+\left(\mathrm{x}(1)^{*} \mathrm{x}(2)\right) /(2 * \operatorname{sqrt}((65 * \mathrm{x}(3) / \mathrm{x}(4))+1))\right) / 2\right)\right.\right. \\
& \wedge 0.875) / 1.7) ;\left(\left(30538325.48 *\left(\mathrm{x}(4)^{\wedge} 4\right) / \mathrm{x}(1)\right) /\left(336000^{*}\right.\right. \\
& \left.\left(\mathrm{x}(2)^{\wedge} 2-\left(\left(\left(4 * \mathrm{x}(4)^{\wedge} 2\right) / \mathrm{x}(1)^{\wedge} 2\right)\right) *(\mathrm{x}(3)-(2.4 * \mathrm{x}(4)) / \mathrm{x}(1))^{\wedge} 4\right)\right)- \\
& \left.(0.001 * \mathrm{x}(3)) ;\left((66116467.27 * \mathrm{x}(1)) /\left(\mathrm{x}(4)^{*} \mathrm{x}(2)^{*} \mathrm{x}(3)\right)\right)-83.3\right]
\end{aligned}
$$

ceq $=[]$; 


\section{- Different Parameters of GA}

Different parameters and its selected values are shown in Table 2.

Table 2: Selected Values of Different Parameters for GA

\begin{tabular}{|l|l|}
\hline Parameters & Selected Values \\
\hline Population Size & 20 \\
\hline Initial Range & {$[0 ; 1]$} \\
\hline Elite Count & 2 \\
\hline Crossover Fraction & 0.8 \\
\hline Generations & 50 \\
\hline
\end{tabular}

\section{RESULTS AND DISCUSSION}

The Figure 2 shows the optimized values of design variables. It plots the vector entries of the individual with the best fitness function value in each generation.

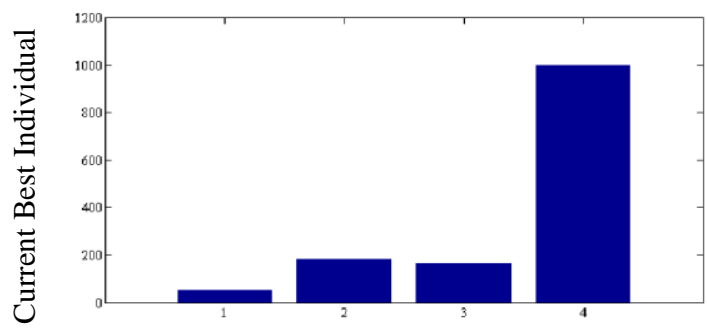

Number of Variables
Figure 3 shows Fitness value vs. Generations. It plots the best function value in each generation versus iteration number. From this graph we conclude that at zero generation fitness value is $11.50^{*} 10^{7}$ and it is decreases upto $6.5^{*} 10^{7}$ at first generation after this it is increases upto $10.95 * 10^{7}$ and remains constant for next generations. Actual and GA values of design variables \& all objective functions are tabulated below in Table 3 .

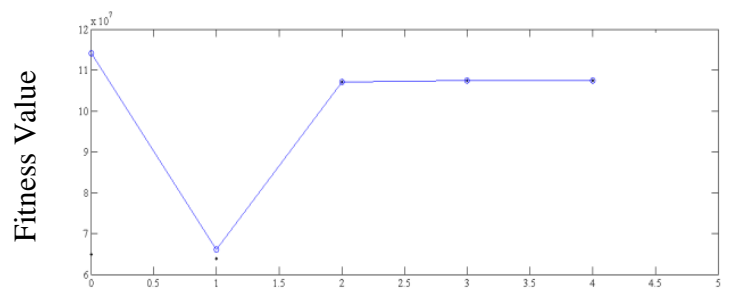

Generations

Figure 3: Fitness Value vs. Generations

Figure 2: Current Best Individual vs. Number of Variables

Table 3: Comparison of values of Design Variables \& all Objective Functions, those are obtained Actually and by using Genetic Algorithm

\begin{tabular}{|l|l|l|l|}
\hline Parameters & Actual & $\begin{array}{l}\text { Rounded Values of } \\
\text { Genetic Algorithm }\end{array}$ & \% Change \\
\hline Gear ratio & 65 & 46 & 29.23 \\
\hline Face width (mm) & 65 & 197 & 23.12 \\
\hline Pitch circle diameter of worm (mm) & 160 & 188 & 21.67 \\
\hline Pitch circle diameter of worm wheel (mm) & 240 & 1000 & 35.90 \\
\hline Volume of worm and worm wheel $\left(\mathrm{mm}^{3}\right)$ & 1560.09 & $1.45442171920^{*} 10^{8}$ & 17.91 \\
\hline Centre distance between worm and worm wheel $(\mathrm{mm})$ & 900.09 & 717 & 20.34 \\
\hline Deflection of worm (mm) & 0.321253 & 0.157242 & 51.05 \\
\hline
\end{tabular}

Above table shows that, there is $17.91 \%$ reduction in volume of worm and worm wheel, $20.34 \%$ reduction in centre distance between worm and worm wheel and $51.05 \%$ reduction in deflection of worm.

\section{CONCLUSION}

In this study the attempt has been made to optimize worm and worm wheel with multiple objectives such as to minimize volume, center distance between worm and worm wheel and deflection of worm. The variables considered are gear ratio, face width, pitch circle diameters of worm and worm wheel. Results shows that, all objectives are satisfied. Therefore GA is one of the best tool for multiobjective optimization problem.

\section{FUTURE SCOPE}

Taking different objectives, design variables and constraints other than above stated more reliable gear pair design may be obtained.

\section{REFERENCES}

[1] R.C. Chakraborty, "Fundamentals of Genetic Algorithm", AI course Lecture notes, Pp.1-39, 2010.

[2] F. Mendi and T. Baskal, "Optimization of module, shaft diameter and rolling bearing for spur gear through genetic algorithm", Expert Systems with Applications, Vol.37, Pp.8058-8064, 2010.

[3] S.S. Rao, "Engineering optimization, theory \& practice", New age international publishers, $3^{\text {rd }}$ edition, 2010.

[4] D.E. Goldberg, "Genetic Algorithms, in search optimization \& machine learning", Pearson education, $4^{\text {th }}$ edition, 2009.

[5] J. Ding, "Intelligent optimization on test bench of electric power steering device in automobile", Vol.4, Pp.367-370, 2010, IEEE.

[6] M. Yaman, H. Saruhan, and F. Mendi, "Power loss optimization of a worm gear mechanism by using genetic algorithm" Technical education faculty, Machine design and construction department, Turkey. 
[7] V. Savsani, R.V. Rao and D.P. Vakharia, "Optimal weight design of a gear train using particle swarm optimization and simulated annealing algorithms”, Mechanism and machine theory, Vol.45 ,Pp. $531-541,2010$.

[8] C. Gologlu and M. Zeyveli, "A genetic approach to automate preliminary design of gear drives", Computers \& Industrial Engineering, Vol.57, Pp. 1043-1051, 2009.

[9] S. Caballero, V. Colomer and R. Romero, "Cylindrical parallel gear trains design by means of genetic optimization", Selected proceedings from the $12^{\text {th }}$ international congress on project engineering, Pp.150-160, 2008.

[10] T.H. Chong and J.S. Lee, "A design method of gear trains using a genetic algorithm", International journal of the korean society of precision engineering, Vol.1, No. 1, Pp.62-70, 2000.

[11] M. Faggioni and F.S. Samani , "Dynamic optimization of spur gears", Mechanism and machine theory, Vol. 46, Pp. 544-557, 2011.

[12] F.J. Szabó, “ Multidisciplinary optimization during gear design”, $6^{\text {th }}$ world congresses of structural and multidisciplinary optimization, 2005.

[13] R. Li, T. Chang, J. Wang and X. Wei, "Multi-objective optimization design of gear reducer based on adaptive genetic algorithm", 978-14244-1651-6, IEEE, 2008.

[14] M. Barbieri and G. Scagliarini, "Optimization methods for spur gear dynamics", ENOC 2008, Saint petersburg, Russia, 2008.

[15] X. Zhang, Z. Hu, C. Lun and J. Yu, "Optimization design of spur gear reducer based on genetic algorithm", 978-1-4244-7161-4/10, IEEE, 2010.

[16] K. Gopinath and M.M. Mayuram, Lecture notes, Machine design II, Indian institute of technology, Madras, Pp.1-19.

[17] C. Yang and H. Wang "Simulated annealing solver of power steering system based neural network", Third international conference on information and computing, 978-0-7695-4047-4/10, IEEE, 2010.

[18] V.B. Bhandari "Design of machine elements", Tata McGraw-Hill education, 2010. 